\title{
A elaboração didática dos gêneros do discurso na produção textual escrita no ensino fundamental
}

\author{
Nívea Rohling da Silva \\ UFSC
}

\begin{abstract}
Resumo
Este artigo discute a maneira como a teoria dos gêneros do discurso tem sido interpretada nas elaborações didáticas na disciplina de língua portuguesa, mais precisamente nas aulas centradas nas produções de textos escritos. A fundamentação teórico-medotodológica insere-se na teoria dialógica da linguagem do Círculo de Bakhtin. Os dados de pesquisa são compostos por produções textuais escritas (gênero anúncio classificado) de estudantes de $7^{\mathrm{a}}$ série do Ensino Fundamental e também de observações dos procedimentos didáticos na condução das atividades de linguagem. Os resultados de pesquisa mostram que ainda persistem, no ambiente escolar, práticas embasadas em uma perspectiva de redação escolarizada em contraposição à noção de produção textual proposta pelos PCN's, que aponta os gêneros do discurso como objeto de ensino das práticas de linguagem.
\end{abstract}

Palavras-chave: Gêneros do discurso, prática de produção textual; gênero anúncio classificado.

\section{INTRODUÇÃO}

A área de ensino de língua materna tem passado por mudanças paradigmáticas acentuadas, e, atualmente, encontra-se confusa com relação a sua função na práxis educativa. $\mathrm{Na}$ escola, é comum ouvir que os alunos não lêem, não interpretam e não possuem mínimas habilidades de leitura e escrita. Há uma distância entre a língua que os alunos falam e a língua ensinada pela escola e, além disso, as propostas de escrita apresentadas, ora pelo professor ora pelos livros didáticos, são descontextualizadas e vazias de significado para os estudantes, pois ainda se constroem textos a partir das conhecidas tipologias textuais: descrição, narração e dissertação. Parece haver uma indefinição com relação aos conteúdos que devem ser priorizados na disciplina de língua portuguesa (LP), e a pedra no sapato do professor chamase produção textual. 
Segundo Geraldi (1993), a problemática na produção textual é produto da carência de uma concepção de linguagem que confira significação à produção escrita do aluno, pois é imprescindível a presença de um interlocutor ativo. No entanto, é comum a inexistência, na produção textual escolar, de um interlocutor a quem o aluno possa dirigir sua voz. Sem perspectiva de um interlocutor e da percepção das condições de produção dos gêneros, as escritas realizadas no âmbito escolar se mostram falsas, sem objetivo, ineficientes na construção da subjetivação do sujeito.

De acordo com Britto (2002), permanece, ainda, com relação à produção de texto escolar, alguns pressupostos como: escrever é um dom, o texto literário é o modelo padrão, o aluno deve ser guiado e não incitado, a avaliação centrada na correção gramatical, o texto avaliado tão somente enquanto produto e não processo. Tais práticas estão ainda muito enraizadas na disciplina de LP, quando a produção de sentidos, nas práticas de linguagem, deveria ser concebida como a unidade básica do ensino em detrimento ao plano gramatical.

Assim, a partir da década de 80, iniciou-se um movimento teórico com intuito de perceber a linguagem numa abordagem que privilegie a interação. Nesse contexto, a teoria dos gêneros do discurso elaborada pelo Círculo de Bakhtin ${ }^{l}$ passou a ser disseminada no Brasil. Atualmente já existem diversos estudos na área, contudo o que se percebe é que ainda não existe uma articulação adequada entre a teorização produzida na academia e o fazer didático do professor.

Diante das problemáticas imbricadas nas práticas de linguagem em sala de aula, mais precisamente na prática de produção textual, este estudo apresenta uma reflexão acerca da maneira como a teoria dos gêneros tem sido interpretada nas aulas de LP. Para tanto, inicialmente são apresentados, brevemente, os conceitos teóricos que embasam esta pesquisa, a saber: um panorama acerca da concepção de produção textual nas aulas de LP e a noção de gêneros do discurso. Na sequência, é apresentado o percurso metodológico, seguido dos resultados da pesquisa, a partir da análise da articulação entre os procedimentos didático-

\footnotetext{
${ }^{1}$ Círculo de Bakhtin, de acordo com Rodrigues (2005), é o termo utilizado pelos pesquisadores para o grupo de intelectuais russos que se reunia regularmente no período de 1919 a 1929, do qual fizeram parte Bakhtin, Volochínov e Medviédiev e outros. Devido às discussões sobre a autoria de alguns textos do Círculo que foram publicados por estes dois últimos autores, mas que são atribuídos a Bakhtin por alguns pesquisadores, muitos optam pela utilização do termo Círculo de Bakhtin, ao invés de se referirem a um dos três autores especificamente. Neste estudo, quando nos referirmos a um dos textos disputados, citaremos ambos os autores, pois não é nosso objetivo discutir a autoria das obras.
} 
pedagógicos na disciplina de LP e as produções textuais escritas de estudantes de ensino fundamental. Salienta-se que esta pesquisa não pretende ser totalizante no sentido de apresentar a realidade do ensino de produção textual, contudo pode apresentar indícios das concepções de produção textual (e de gêneros do discurso) inseridas no espaço escolar, como também refletir sobre a elaboração didática dos gêneros no âmbito escolar.

\section{PANORAMA DAS PRÁticAS DE PRODUÇÃO TEXTUAL NAS AULAS DE LÍNGUA PORTUGUESA}

A disciplina de LP tem passado por acentuadas mudanças e isso se deve, em grande medida, às orientações dos documentos oficiais de ensino em apontar os gêneros do discurso como um novo objeto de ensino-aprendizagem nas práticas de linguagem em sala de aula. Contudo, segundo Rodrigues (1999), as recentes pesquisas em linguística aplicada (LA) têm mostrado que o fracasso escolar no ensino de língua tem girado em torno, principalmente, de um ensino-aprendizagem voltado para a questão da metalinguagem, ou para aspectos formais de leitura e da escrita.

Na perspectiva de Rojo (2001), houve um avanço considerável a partir dos estudos da linguística textual e das teorias de cunho cognitivistas de processamento e memória, trazendo para o centro da discussão o texto como unidade de trabalho. Porém, de acordo com a autora, esses estudos ainda se mostram ineficientes no desenvolvimento de cidadãos capazes de interagir criticamente com os discursos alheios e com o próprio discurso. Isso quer dizer que tal virada pragmática no ensino de língua ainda não é uma realidade.

Nesse cenário, os PCN's de LP surgem em 1997, constituindo-se documento oficial de ensino e trazendo consigo a característica de ser um norte à prática docente, até então delineada pelos materiais didáticos, no ensino fundamental e pelas provas de vestibular, no ensino médio. Esse novo direcionamento foi positivo em face à necessidade de tal documento. Os PCN's priorizam as práticas de leitura, práticas de produção textual e práticas de análise linguística; mais que priorizar, os PCN's conferem a esses três eixos o estatuto de conteúdo a ser ensinado nas aulas de LP².

\footnotetext{
${ }^{2}$ Delimitou-se, nesta pesquisa, a reflexão sobre questões teóricas concernentes à prática de produção textual escrita, tendo em vista que a análise dos três eixos (leitura, produção textual e análise linguística) mostra-se demasiado ampla.
} 
Bonini (2002), em seu artigo intitulado "Metodologias do ensino de produção textual: a perspectiva da enunciação e o papel da Psicolinguística", recupera o percurso histórico da produção textual em LP a partir dos anos 60. Em termos das orientações para o ensino de produção textual, o autor aponta a existência, na atualidade, de duas vertentes: (1) a interacionista - a produção textual como reprodução de um corpo de tradições de uma comunidade, e (2) a enunciativista - entendida como trabalho e exercício de subjetividade na linguagem. Esta tem tido maior acolhimento entre os documentos oficiais. No decorrer do texto o autor menciona a problemática envolvida nas práticas de escrita em sala de aula. Segundo Bonini (2002), a partir dos anos 80, buscou-se inserir no contexto escolar a perspectiva de entender a linguagem como um meio em que o homem existe e age eliminando-se o caráter prescritivista. Passou-se a considerar o texto e sua enunciação como a unidade básica do ensino, deslocando a frase e sua gramática para segundo plano.

Entretanto, como dito anteriormente, esta mudança paradigmática ainda não é uma realidade na concepção de linguagem postulada pela escola, menos ainda nas práticas de produção textual. De acordo com Britto (2002), uma situação bem comum na produção textual observada em aulas de LP constitui-se em:

[...] caracterização da redação escolar enquanto um gênero escolar, que se subdivide em dissertação, narração e descrição, desvinculado do exercício efetivo de leitura e escrita, que se realiza no interior de uma disciplina. [...] A concepção subjacente é a de que leitura e escritura são habilidades independentes do domínio dos discursos que portam e que o sujeito pode adquiri-la com treino e assimilação de regras. (Britto, 2002, p. 108-109)

Através da questão apontada pelo autor, percebe-se o deslocamento da prática de escrita do aluno do seu contexto social, a caracterização mencionada pelo autor constitui os gêneros escolarizados ${ }^{3}$, que têm por objetivo o treino de escrita. A própria terminologia adotada redação escolar traz implícita a idéia de uma escrita para fins de treinamento. Partese do pressuposto de que ao dominar uma determinada estrutura, garantir-se-á ao estudante o domínio de qualquer texto que, supostamente, tenha a mesma estrutura textual. Tal posicionamento pode ser questionado, uma vez que fora dos domínios escolares dificilmente será solicitado ao estudante que faça uma narração ou uma descrição; quanto à dissertação, esta será talvez solicitada em concursos e vestibulares que, por sua vez, já estão adotando em suas propostas os gêneros do discurso.

\footnotetext{
${ }^{3}$ Os gêneros escolarizados são criados pela escola (narração, descrição, dissertação), distante dos gêneros que circulam socialmente; o termo no presente trabalho traz consigo uma crítica a essa prática.
} 
Dentro dessa discussão, Geraldi (1993) estabelece uma dicotomia entre produção textual e o ensino de redação. Segundo o autor, ao trabalhar com redação, os textos são produzidos para a escola; já na perspectiva da produção textual produzem-se textos na escola. Em qualquer modalidade, para se produzir um texto é necessário que: se tenha o que dizer, se tenha uma razão para dizer, se tenha um interlocutor desse dizer. Na produção de textos, mesmo em uma simples conversa cotidiana, o projeto discursivo se apresenta, ou seja, o interlocutor tem algo a dizer, tem um discurso a materializar, enquanto na redação o projeto discursivo inexiste. Dessa maneira, percebe-se nas redações muita escrita e pouco texto (pouco discurso), pois o projeto discursivo não está claro para o estudante (Geraldi, 1993).

Ao propor um texto sem que se tenha um querer-dizer e, principalmente, para quem dizer - interlocutores reais - a atividade se desenvolve mecanicamente. Exercícios de escrita a partir da observação de uma gravura, sem o estabelecimento de uma interação, sem que o estudante tenha algo relevante a dizer, constituem atividades de preenchimento. Exercícios de redação que o preparam para um depois, e não para uma relação interdiscursiva, mostram-se artificiais e infrutíferos na construção de sujeitos-autores de seus textos e produtores de sentidos e discursos.

Com relação à idéia de preenchimento, Britto (2002, p. 109) referencia a pesquisa de Lemos (1997) com redações de vestibular: “o vestibulando, premido pela necessidade de escrever, trata de preencher o papel com frases de efeito, noções vagas e de valor absoluto, ao invés de engajar-se em uma linha argumentativa própria”. Esse espaço de escrita restringe o desenvolvimento da subjetividade do estudante, tomando a produção escrita como uma habilidade relacionada ao treino e assimilação de regras. A estratégia do preenchimento está, pois, ancorada na total ausência de um interlocutor definido a quem se tem algo real a dizer.

Para Rodrigues (1999, p. 99), “o ensino de produção textual, centrado em uma tipologia textual formal (narração, descrição, dissertação) aponta para a falta de uma prática de aprendizagem centrada nos processos discursivos". A partir desse panorama teóricometodológico surge a proposta teórica enunciativista que aponta os gêneros do discurso como objeto de ensino nas práticas de linguagem na disciplina de LP. Não mais o texto como estrutura tipológica, mas o gênero na perspectiva sócio-discursiva, despontando como um aporte produtivo e significativo para o trabalho reflexivo das práticas de linguagem. Algumas pesquisas já têm se desenvolvido, no âmbito da LA, dentro dessa perspectiva. Nessa direção, 
pode-se mencionar as pesquisas que privilegiam as relações discursivas na produção de texto (Lemos-Rossi, 2002; Rojo, 1996) e também os trabalhos que propõem a elaboração didática de alguns gêneros (Haeser, 2005; Bussarelo, 2005). A partir de pesquisas como estas, abre-se um caminho novo e de grande potencial heurístico para novas abordagens de ensino de língua, sobretudo, da prática de produção textual escrita.

Na próxima seção, será apresentada a noção de gêneros do discurso que baliza a análise dos dados.

\section{OS TIPOS RELATIVAMENTE ESTÁVEIS DE ENUNCIADOS: OS GÊNEROS DO DISCURSO}

O conceito de gênero é apresentado em muitos textos do Círculo de Bakhtin e a sua terminologia oscila entre formas de discurso social, formas de um todo e tipos de interação verbal (Rodrigues, 2005). Entretanto, no texto intitulado "Os gêneros do discurso", onde a questão dos gêneros é detalhada, Bakhtin opta pelo termo 'gêneros do discurso', termo este que acabou sendo também o nome mais utilizado nas pesquisas em LA que seguem tal enfoque ${ }^{4}$. No referido texto, Bakhtin ([1979]2003) define os gêneros do discurso como "tipos relativamente estáveis de enunciados", ou seja, através de enunciados individuais que se movimentam em direção a uma regularidade surge o gênero, e essa relativa estabilização acontece através de seu uso em interações concretas.

Uma vez definidos como tipos relativamente estáveis de enunciados, os gêneros carregam em si um caráter flexível e plástico. Nessa definição, a palavra relativamente é fundamental; é ela que denota a flexibilidade do gênero, a qual está diretamente ligada às interações sociais. Se as relações humanas são complexas, as mudanças, ininterruptas, e os gêneros constituem-se a partir das atividades humanas, conseqüentemente, eles irão refletir as mudanças histórico-sociais. Uma vez que as interações humanas estão em constante

\footnotetext{
4 Em Rojo (2005), no texto intitulado "Gêneros do discurso e gêneros textuais: questões teóricas e aplicadas" há uma discussão sobre a diferença teórico-metodológica envolvida no uso das terminologias: teoria de gêneros do discurso ou discursivos e teoria dos gêneros de texto ou textuais. Para a autora, ambas as leituras estão ancoradas em diferentes leituras bakhtinianas, mas a distinção está no fato de que a primeira centra seu estudo nas situações de produção dos enunciados ou textos e em seus aspectos sóciohistóricos, e, a segunda, na descrição da materialidade do texto.
} 
constituição, os gêneros possuem, então, a mesma característica de não-acabamento do enunciado.

Ainda sobre a conceituação de gêneros, de acordo com Rodrigues, Bakhtin concebe os gêneros como "tipificação social dos enunciados que apresentam certos traços (regularidades) comuns, que se constituíram historicamente nas atividades humanas, em uma situação de interação relativamente estável” (Rodrigues, 2005, p. 164). Assim, segundo Rodrigues (2005), é necessário olhar os gêneros a partir de sua historicidade, já que não são unidades convencionais, mas sim, tipos históricos de enunciados, possuindo a mesma natureza do enunciado (natureza social, discursiva e dialógica).

De acordo com Bakhtin (2003), a diversidade dos gêneros é infinita porque são inesgotáveis as possibilidades das atividades humanas e cada esfera comporta um repertório de gêneros do discurso que vai se diferenciando e se ampliando à medida que a própria esfera se desenvolve e torna-se mais complexa. Ao estabelecer a noção de gênero, o autor apresenta uma classificação dos gêneros como: primários e secundários. Os gêneros primários são aqueles ligados às esferas cotidianas de interação, podendo, muitas vezes, transformar-se e assumir estatuto de gênero secundário, tendo em vista a dinamicidade e plasticidade inerente aos gêneros. Já os gêneros secundários, segundo Bakhtin, "surgem nas condições de um convívio cultural mais complexo e relativamente desenvolvido e organizado (predominantemente escrito) [...]" (Bakhtin, 2003, p. 263) e, por sua vez, demandam uma complexidade maior, sendo exemplos, o romance, os gêneros científicos, jornalísticos, entre outros.

Já com relação ao surgimento de novos gêneros, pode-se dizer que esse processo se dá a partir das demandas sociais, pois um gênero surge ou desaparece em função das condições sócio-discursivas. Nessa mesma perspectiva, Geraldi (2006) propõe que a emergência de novos gêneros está associada às atividades sociais, e que, quanto mais complexa é uma sociedade, mais complexos, e em maior número, são os gêneros nela construídos.

$\mathrm{Na}$ contemporaneidade, tem-se observado o surgimento e o desaparecimento de diversos gêneros. Rodrigues (2005) cita, como exemplo de gêneros que desapareceram de circulação social, as conversas de salão e o romance-folhetim. Já outros gêneros surgem de uma espécie de transmutação, como, por exemplo, gêneros encontrados no suporte digital: o 
$b \log ^{5}$, que lembra o diário, o e-mail, que possui características da carta. Todavia, os novos gêneros não substituem os já estabelecidos: o telefonema não substituiu a conversa, o artigo assinado não excluiu o editorial (Rodrigues, 2005). Não se trata de uma relação de substituição, e sim, do aparecimento de gêneros a partir das novas necessidades de interlocução, o que ocorre através das mudanças sócio-históricas, repercutindo nas relações de subjetividade e alteridade dos sujeitos.

A origem dos gêneros, bem como seu processo de mudança, também é discutida por Todorov $(1980)^{6}$ no escopo do literário, porém essa reflexão também é válida para o presente estudo, uma vez que está em consonância com a teoria bakhtiniana dos gêneros do discurso. Na perspectiva de Todorov (1980, p. 46), "Um novo gênero é sempre a transformação de um ou de vários gêneros antigos [...]”. Ainda dentro do escopo literário, mas no que se refere a uma teoria geral dos gêneros, o autor pontua que, ao se pensar em temporalidade, não há nada "anterior aos gêneros", pois nunca houve literatura sem gênero. Ele propõe que tanto os gêneros literários, quanto os que não estão dentro deste limite, ou seja, os gêneros das demais esferas sócio-discursivas, têm por origem o discurso humano, e que sua constituição se dá a partir de práticas sociais. A mola propulsora do aparecimento ou desaparecimento de um gênero são as necessidades comunicativas intrínsecas às práticas de interação social. Somente as necessidades discursivas, surgidas nas interações humanas, propiciam o surgimento e modalizam os modos sociais de dizer, a saber, os gêneros do discurso.

Em resumo, os gêneros norteiam as interações sociais e, ao mesmo tempo, são por elas norteados; apresentam flexibilidade para as organizações dos enunciados; servem como baliza para o dizer social; trazem, intrinsecamente, todo um universo axiológico. Os sujeitos interagem por meio dos enunciados construídos dentro de um determinado gênero e, por meio do enunciado e do seu gênero, expressam suas concepções de mundo, suas crenças, seus valores, revelando, não raras vezes, a voz do outro que compõe seu discurso, e formando, desse modo, uma cadeia ininterrupta de sentidos. Dessa maneira, compreende-se a posição central que os gêneros ocupam na arquitetura do pensamento bakhtiniano.

Após as inferências teóricas sobre a prática de produção escrita escolar e o conceito de gênero sobre o qual se embasa esta pesquisa, será apresentado o percurso metodológico da

\footnotetext{
${ }^{5}$ Blog pode ser traduzido por diário na rede. Sobre esse assunto ver: Komesu (2005).

${ }^{6}$ É importante ressaltar que Tzvetan Todorov foi um leitor de Bakhtin, embasando-se nesse autor para elaborar sua construção teórica sobre os gêneros do discurso. Contudo, nesse texto, Todorov não faz alusão à teoria bakhtiniana.
} 
pesquisa, com vistas à apreensão da maneira como a teoria dos gêneros do discurso tem sido interpretada (e elaborada) nas aulas de LP.

\section{PERCURSO METODOLÓGICO DA PESQUISA}

Buscou-se, nesta pesquisa, apreender a forma como a teoria dos gêneros do discurso tem sido interpretada nas aulas de LP. Assim, como dito antes, este estudo tem como referência teórico-medotodológica a teoria dialógica da linguagem do Círculo de Bakhtin. Os dados de pesquisa são compostos por produções textuais escritas (gênero anúncio classificado) de estudantes de $7^{\text {a }}$ série do Ensino Fundamental ${ }^{7}$ e também de relatos de observações dos procedimentos didáticos na condução das atividades de linguagem. Foram observadas as interações pedagógicas ocorridas em 16 aulas de LP durante o mês de outubro/2007.

Durante a análise, buscou-se perceber a articulação entre os procedimentos didáticos evidenciados nas interações pedagógicas (e que foram observados pela pesquisadora durante as aulas de LP), configurando a relação estudante/professor, e os textos escritos produzidos pelos alunos nas aulas observadas.

\section{O TRATAMENTO DIDÁTICO DOS GÊNEROS NAS AULAS DE LP}

Durante a observação das interações pedagógicas, o que foi mais perceptível é que, na maioria das vezes, as aulas foram dedicadas a exercícios estruturais de gramática. Em uma dessas ocasiões, a professora iniciou a aula a partir de correção de exercício estrutural de colocação pronominal em orações isoladas, solicitou aos alunos que lessem e dissessem a posição do pronome em relação ao verbo e justificassem o uso deste. Na sequência, a professora disse ao grupo que iriam trabalhar produção textual e solicitou-lhes que abrissem o livro didático (LD). Iniciou-se a leitura do tópico de proposta de produção textual (alguns alunos leram para o grupo). A condução da proposta levou em torno de dez minutos. O que

\footnotetext{
${ }^{7} \mathrm{Na}$ ocasião da pesquisa, o Ensino Fundamental ainda era composto de 8 anos letivos.
} 
ficou saliente na prática da professora é que a leitura indicada pelo LD serviu de alimentação temática para a proposta que viria a seguir: "Você é a favor do Clone? Com base nos textos lidos escreva um texto dissertativo”. A professora solicitou aos estudantes que fizessem um rascunho no caderno e depois passassem a limpo.

Foram observados na condução didática da aula os seguintes aspectos: a falta de uma discussão sobre os diferentes gêneros lidos no LD (charge, entrevista, carta do leitor); a ausência de uma discussão temática sobre o gênero em estudo; a ausência de material alternativo (além do LD). Assim, o condutor da aula era o LD; a intervenção pedagógica foi mínima. Durante a aula, percebeu-se: (1) o desinteresse do grupo (alguns perguntavam aos colegas: “- é pra fazer de acordo com o livro ou o que a gente pensa?” Resposta: “- os dois; pega o modelo do livro.”) e (2) a presença de perguntas recorrentes em aulas de LP: “Vale nota professora? É pra entregar nesta aula? Como começo? Pode mudar o título?".

Tais questionamentos dos estudantes revelam perspectivas acerca da produção textual perpetuadas pela escola: a) escrita de texto com objetivo de correção de erros gramaticais; b) o que os estudantes têm a dizer é irrelevante; c) tem-se um modelo a seguir. A aula de produção textual ocorreu em pouco mais de 30 minutos e não houve discussão por parte dos alunos. Ao questionar os estudantes sobre a frequência com que escrevem textos, foi relatado à pesquisadora que as produções escritas são bem escassas em relação aos conteúdos gramaticais. Ou seja, não é uma prática priorizada.

Em outra aula observada, também houve produção textual, contudo, ao invés de um gênero escolarizado, foi trabalhado um gênero discursivo pertencente à esfera jornalística anúncio classificado. De maneira semelhante à aula de produção de texto relatada anteriormente, a professora solicitou que o grupo abrisse o livro na página em que constava a proposta de produção textual. A abordagem da professora em relação ao gênero anúncio classificado transcorreu da seguinte maneira: a professora, rapidamente, fez a leitura do livro e lançou a proposta: "Vocês serão vendedores e irão montar classificados. Ao final da aula entregar em uma folha. Leiam as instruções do livro"; o encaminhamento da proposta de escrita levou aproximadamente dez minutos.

Foi interessante observar que o LD apresentava dois exemplos de anúncio classificado, contudo, somente o primeiro foi lido com o grupo. Na sequência do primeiro classificado, o LD propõe uma atividade de exploração do gênero em questão, porém tal 
atividade foi totalmente desconsiderada pela professora, o que, a nosso ver, constitui-se em perda, pois, a partir dessa atividade, o grupo poderia ter uma caracterização mais acurada do gênero, para posterior produção. Em nenhum momento os estudantes foram instigados a refletir sobre as condições de produção e de circulação de um classificado; através de questões como: Quem escreve esse gênero discursivo? Com que finalidade? Onde? Quando? Como? Com base em que informações? Quem lê esse gênero? Como o classificado surgiu? Onde circula? Enfim, questões que levariam os estudantes a refletir sobre as condições de produção do gênero e que os levaria a ter parâmetros para o que escreveriam posteriormente. É interessante ressaltar que nem mesmo as características textuais e verbais dos classificados foram abordadas.

Nas práticas de linguagem ancoradas na perspectiva dos gêneros discursivos, considera-se relevante apresentar o jornal aos alunos para que eles tenham um contato com o gênero em seu suporte original. Dessa maneira, os estudantes podem inferir a importância dos classificados no jornal, de acordo com sua localização no espaço do jornal, perceber os objetos mais anunciados: o que pode ser alugado, comprado, vendido, enfim percepções oferecidas somente pelo suporte original.

Para que o aluno seja um leitor proficiente na leitura de determinado gênero discursivo e para que, posteriormente, possa produzi-lo em uma situação concreta de enunciação, devese possibilitar ao estudante o contato com o gênero. É imprescindível, para apropriação do gênero, que se façam várias leituras do gênero proposto. Enfim, que seja viabilizado ao grupo de alunos um contato mais efetivo com o gênero, uma vez que a leitura de um modelo a seguir em nada ajudará o estudante no momento da compreender o funcionamento discursivo do gênero. E ainda mais se tratando de classificados, pois não há maiores dificuldades de acesso, principalmente em um colégio da rede particular que possui laboratório de informática com acesso à Internet. Nesse contexto, o grupo poderia ler anúncios classificados de jornais virtuais; dessa forma, além de perceber a circulação do gênero em um outro suporte midiático (digital), a tecnologia poderia ser utilizada nas aulas de LP de forma interativa.

Outra questão relevante a ser discutida sobre a elaboração didática do gênero é a circulação dessa escrita. Por que não fazer anúncios classificados a partir de objetos pertencentes aos alunos? A professora poderia propor a venda, troca e compra de objetos dos próprios alunos e anexar no mural da escola. A proposta do faz de conta não se sustenta mais, 
tendo em vista as novas orientações didáticas para o tratamento do gênero, conforme explorado na fundamentação teórica desta pesquisa.

Com a permanência de procedimentos didáticos como os que foram aqui relatados, a escrita do aluno continua nos moldes tradicionais da redação escolarizada, aprisionada, sem interlocutor real e sem uma função discursivo-axiológica que confira ao dizer do aluno um indício de autoria e subjetivação.

Em resumo, por mais que sejam mencionados nas aulas de LP, os gêneros do discurso estão longe de serem abordados em sua dimensão sócio-discursiva. Nas interações pedagógicas observadas, pode-se dizer que o gênero anúncio classificado foi tomado como uma tipologia de texto, distanciando-se da noção de gênero como lugar de interação discursiva.

\section{A ARTICULAÇÃo ENTRE A ELABORAÇÃo DIDÁTICA DO GÊNERO E A PRODUÇÃO TEXTUAL ESCRITA DOS ESTUDANTES}

Como dito anteriormente, foram analisados textos escritos produzidos pelos estudantes da $7^{\mathrm{a}}$ série, cujas condições de produção foram relatadas na seção anterior. A partir da elaboração didática dispensada à produção do gênero anúncio classificado, cujos procedimentos didáticos estão ancorados nos moldes da redação escolarizada, as produções escritas, em sua maioria, mostraram-se distante do gênero anúncio classificado.

Foram analisados 17 textos do gênero (anúncios classificados) dos quais foram selecionados três para apresentação neste trabalho. A escolha se deu a partir do critério de aproximação do gênero.

O primeiro texto é o que mais se aproxima do gênero anúncio classificado tanto no que se refere ao conteúdo temático, como também às características linguístico-textuais do gênero; no segundo texto, tem-se uma aproximação mediana e, por fim, no terceiro texto selecionado, percebe-se um acentuado distanciamento das características do gênero anúncio classificado, como se pode verificar na análise a seguir: 


\section{Análise do texto 1}

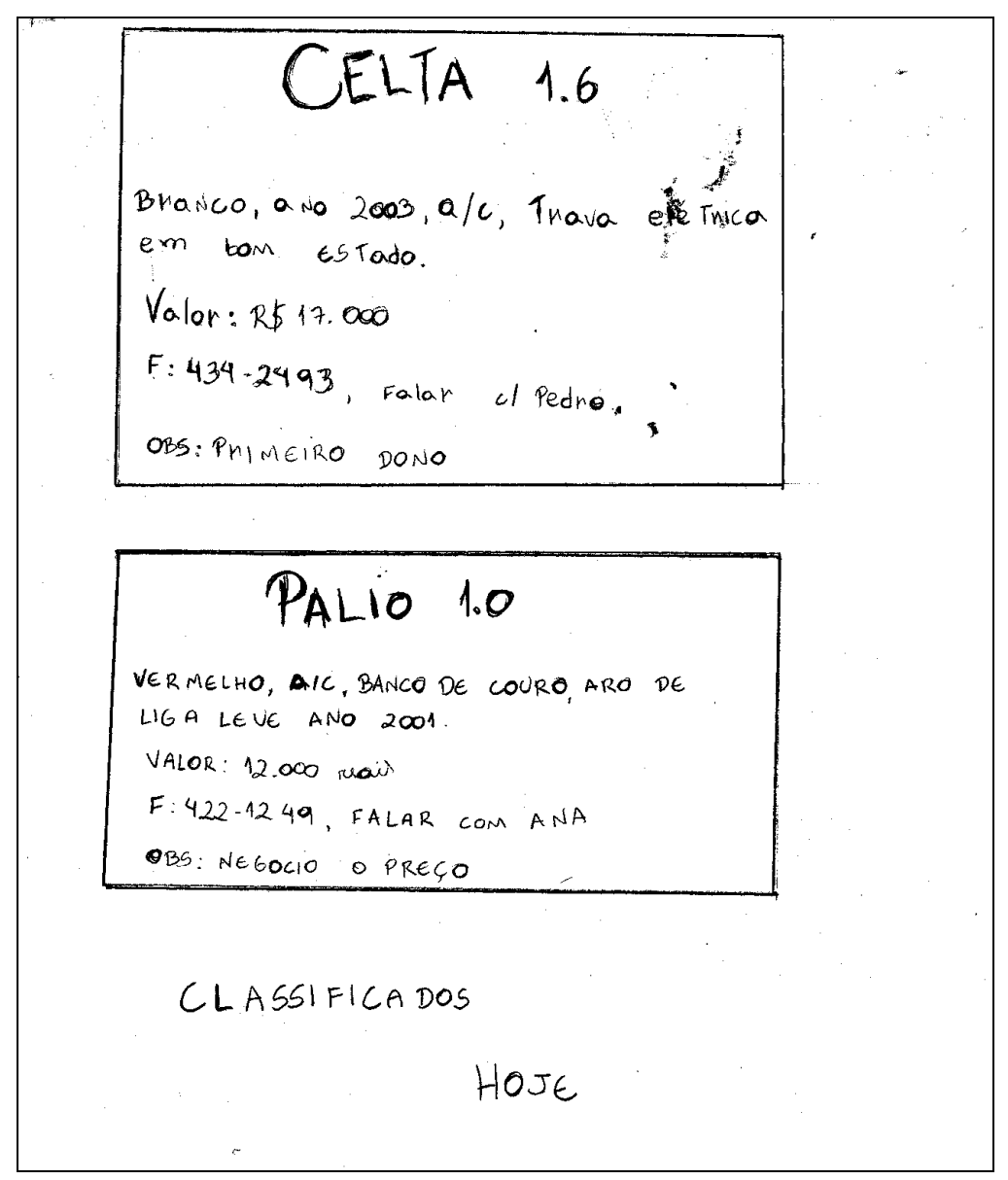

Figura 1 - Texto produzido pelo aluno A.

O primeiro texto, conforme Figura 1, mostra-se mais próximo a um anúncio classificado, tanto do ponto de vista da diagramação como também em relação ao conteúdo temático do texto. $\mathrm{O}$ estudante tentou reproduzir as características elementares do gênero, evidenciando o produto que se quer vender, alugar ou comprar, neste caso, um veículo. $\mathrm{Na}$ diagramação, o estudante utilizou letras em maiúsculo e negrito, o que confere destaque à finalidade discursiva do gênero anúncio classificado, a saber, a divulgação de um produto (automóvel) que está à venda. Ainda nessa perspectiva, observou-se que o texto se apresenta em boxes, o que pode ser interpretado como uma tentativa de reproduzir o padrão do jornal e também do exemplo proposto pelo LD. As demais informações aparecem em forma simplificada, o que é típico do gênero, devido ao espaço reduzido e o custo de se publicar em 
jornais, geralmente avaliados pelo número de linhas. No que se refere aos aspectos relativos ao conteúdo temático, o texto se mostra adequado ao gênero, pois as informações como cor, ano e preço do veículo anunciado, bem como o telefone de contato da pessoa que está vendendo, constam no anúncio; enfim há a inserção de dados fundamentais presentes nesse gênero, que se constituem como "peças" fundamentais para que se cumpra a finalidade discursiva do gênero.

\section{Análise do texto 2}

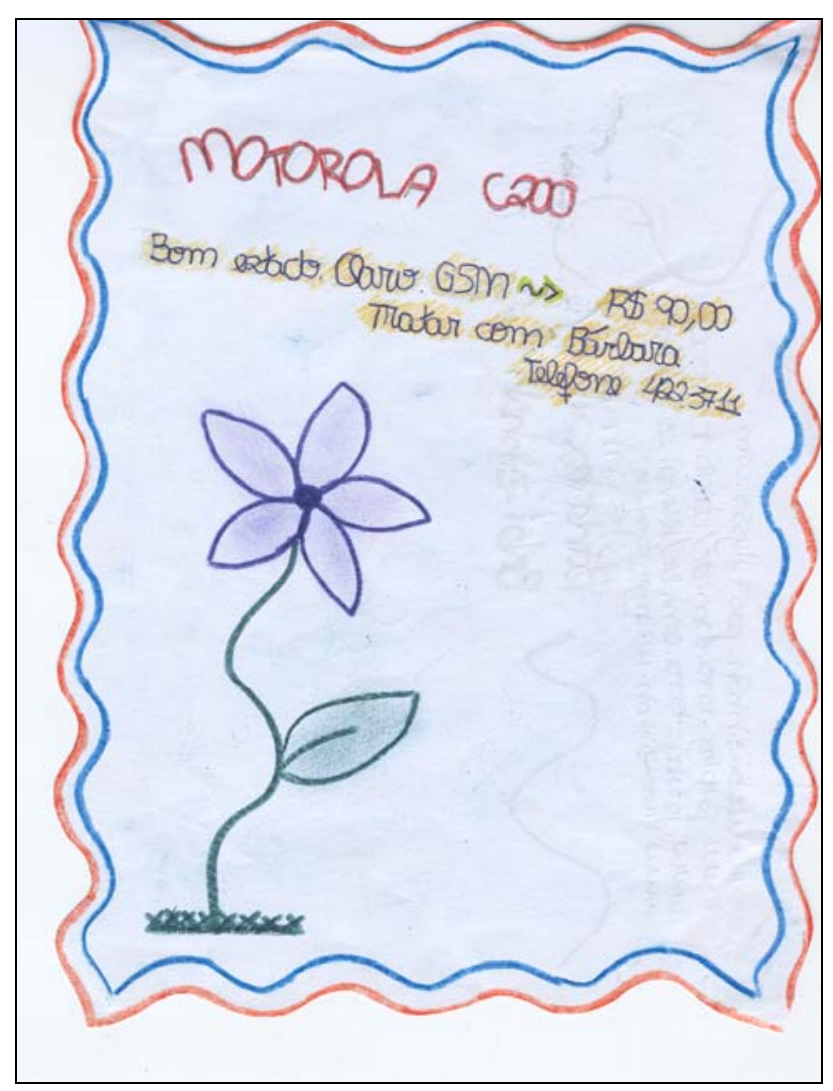

Figura 2 - Texto produzido pelo aluno B.

O texto 2, por sua vez, revela uma aproximação mediana com o gênero trabalhado, pois ao analisar os aspectos discursivos, percebe-se a inserção das informações necessárias para que se cumpra o propósito discursivo do gênero, ou seja, o produto a ser vendido (celular) é apresentado de maneira destacada, bem como o preço e contato da pessoa que vende o produto. Porém, já com relação ao aspecto composicional, o texto está distante das 
características típicas desse gênero; tanto o desenho de uma flor quanto o excesso de cores não trazem ao leitor a impressão de estar lendo um anúncio classificado. O estudante percebeu as características oriundas do horizonte temático, entretanto, "escapou-lhe" a percepção do aspecto composicional.

Pode-se dizer que os textos dos estudantes que mais se aproximaram do gênero anúncio classificado, tanto no aspecto composicional quanto nas características discursivas (temáticas), o fizeram a partir de outras interações que não leituras analíticas realizadas em sala de aula, uma vez que, como dito anteriormente, durante as interações pedagógicas não ocorreram leituras direcionadas no sentido de analisar enunciados do gênero e perceber a forma com o se interage por meio do anúncio classificado. Os textos que mais se assemelham ao gênero trabalhado podem ter sido produzidos a partir do exemplo do LD e também de leituras prévias do gênero em interações cotidianas. 


\section{Análise do texto 3}

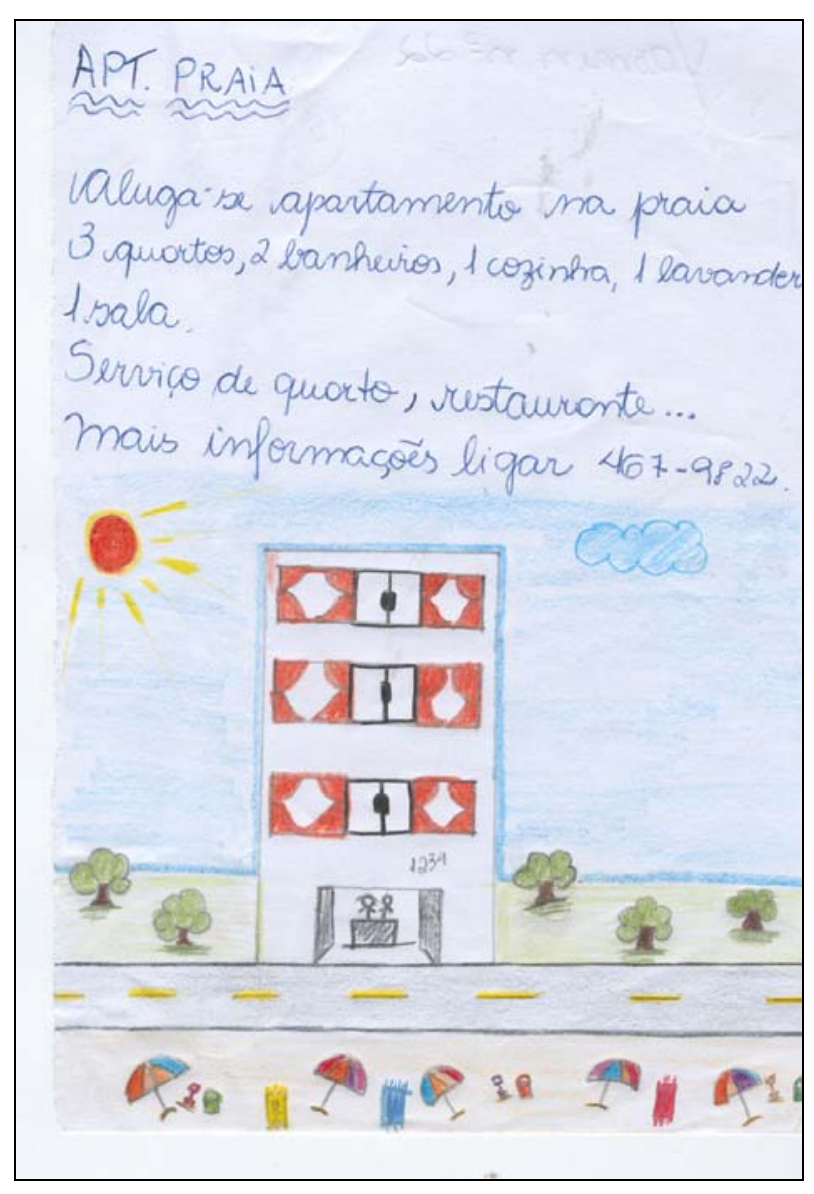

Figura 3 - Texto produzido pelo aluno C.

Por fim, com relação ao texto 3, a primeira questão a ser pontuada é a enorme distância entre um anúncio classificado de real circulação e o texto produzido pelo estudante, no que tange ao aspecto da composição. O estudante tenta retratar através de desenho a casa que seria alugada; ao desenhá-la, ele pode estar se referindo às fotografias que alguns anúncios trazem na seção de imóveis, ou até mesmo a uma relação com o gênero propaganda publicitária, mas o que fica perceptível é a que a apresentação visual se mostra bastante distante de um anúncio classificado. Já na perspectiva do conteúdo temático, o anúncio se mostra um tanto confuso, pois o objetivo é anunciar uma casa de praia disponível para ser alugada, porém, após a caracterização da casa, propõe o serviço de quarto e restaurante, ou seja, características de um hotel e não de uma casa de praia a ser alugada. 
Isso mostra que o estudante, ao produzir seu texto, não conhece o funcionamento discursivo do gênero e lhe falta uma leitura mais aprofundada do mesmo, não tendo claro o que de fato quer anunciar e qual o repertório linguístico necessário para fazê-lo. Na produção textual, observa-se que não se tem claro o objetivo discursivo, o que nos leva a pensar que se talvez a proposta partisse de uma situação real como, por exemplo, anexar no mural do colégio anúncios dos estudantes, em que eles pudessem anunciar objetos que quisessem trocar, vender, comprar (álbuns de figuras, Cd's, livros, revistas, etc.), os estudantes teriam um objetivo discursivo definido e, dessa maneira, poderiam, de fato, interagir a partir desse gênero.

Os três textos selecionados para esta discussão mostram, em certa medida, o conhecimento prévio que os estudantes já possuíam sobre o gênero, uns mais e outros menos, e, principalmente, revelam a intervenção pedagógica realizada em sala de aula, ou melhor, evidenciam a falta de uma abordagem de gênero em sua essência. Ficou evidente a necessidade de levar o grupo a refletir sobre o gênero em sua plenitude, tendo em vista que, a partir de uma leitura crítica do gênero trabalhado, seria possível levar os estudantes a uma percepção da dimensão discursiva (social) do gênero, como também da dimensão verbal do gênero, que envolve os aspectos linguístico-textuais. Segundo Rodrigues (2005, p. 9), “o enunciado é composto por duas dimensões inextricáveis: dimensão verbal-textual e a dimensão social". Ambas as dimensões precisam ser levadas em consideração no trabalho com o gênero.

\section{CONSIDERAÇÕES FINAIS}

A teoria dos gêneros do discurso tem sido apontada como uma área fértil em pesquisas de LA, entretanto, ainda há lacunas entre as pesquisas publicadas (e discutidas) em espaços acadêmico-científicos e as concepções didático-pedagógicas que circulam na escola. O objetivo desta pesquisa foi justamente pinçar alguns indícios que apontem para a percepção que se tem, no âmbito escolar, sobre o trabalho com os gêneros do discurso. A partir da análise aqui apresentada, percebeu-se que, não raras vezes, a teoria dos gêneros do discurso tem sido interpretada (e, por isso, didatizada) novamente como uma categoria de textos, priorizando aspectos formais e estruturais do texto em detrimento aos aspectos interacionais e 
discursivos imbricados na concepção de gênero. Foi possível evidenciar, neste artigo, que o trabalho com o gênero na escola ainda não extrapolou a dimensão estrutural, tendo em vista que os aspectos interacionais (discursivos) são ainda inexplorados nas mediações pedagógicas.

Além disso, vale salientar que, a partir da noção de gênero ligada às interações sociais, o trabalho didático com os textos em sala de aula precisa ser mediado a partir de uma exploração prévia dos gêneros a serem trabalhados, evidenciando aos estudantes as interações que se estabelecem por meio deles. Antes de propor aos alunos a escrita de determinado gênero, cabe ao professor explorar com o grupo de alunos alguns aspectos relativos ao funcionamento do gênero, por exemplo: porque se produz determinado gênero, ou seja, qual a finalidade discursiva; quem são os interlocutores na interação discursiva; em quais suportes os gêneros circulam. Enfim, a partir de uma discussão sobre as condições de produção do gênero e dos aspectos discursivos dos mesmos, o aluno poderá apreender a dinâmica de determinada interação discursiva (ou seja, do gênero) e, desse modo, talvez seja possível uma mudança significativa nas práticas de leitura e de produção textual escrita.

Em resumo, muito ainda há para ser trilhado pela LA no trabalho com gênero. Segundo Faraco (2001), deve-se reconhecer Bakhtin não somente em sua importância histórica, mas, sobretudo, no poder heurístico de suas idéias. A partir do momento que a teoria dos gêneros for compreendida em sua essência, na esfera escolar, e suas elaborações forem condizentes com a referida teoria, há a possibilidade de práticas didático-pedagógicas mais frutíferas no campo da linguagem.

\section{REFERÊNCIAS}

Bakhtin, M. \& Voloschinov, V. N. (2004). Marxismo e filosofia da linguagem: Problemas fundamentais do método sociológico na ciência da linguagem. Tradução do francês por Michel Lahud e Yara F.Vieira. 11 ${ }^{\mathrm{a}}$ ed. São Paulo: Hucitec.

Bakhtin, M. M. (2003). Estética da criação verbal. Tradução do russo por Paulo Bezerra. $4^{\mathrm{a}}$ ed. São Paulo: Martins Fontes.

Bonini, A. (2002). Metodologias do ensino de produção textual: A perspectiva da enunciação e o papel da Psicolinguística. Perspectiva, 20(1), 23-47. Revista do Centro de Ciências da Educação da UFSC, Florianópolis. 
Brasil, SEF. (1998). Parâmetros curriculares nacionais: Terceiro e quarto ciclos do ensino fundamental: língua portuguesa. Brasília: MEC/SEF.

Britto, L. P. L. (2002). A sombra do caos: Ensino de língua x tradiçãogramatical. Campinas, SP: Mercado de Letras, ALB.

Bussarelo, J. M. (2005). O ensino aprendizagem da produção textual escrita na perspectiva dos gêneros do discurso: A crônica. Dissertação de mestrado. Universidade Federal de Santa Catarina.

Faraco, C. A. (2001). Bakhtin e os estudos enunciativos no Brasil: Algumas perspectivas. In: Brait, Beth (Org.). Estudos enunciativos no Brasil: Histórias e perspectivas. São Paulo: Fapesp.

Geraldi, J. W. (1993). Portos de passagem. São Paulo: Martins Fontes.

Haeser, M. E. (2005). O ensino aprendizagem da leitura no ensino médio: Uma proposta a partir de oficina com o gênero carta do leitor. Dissertação de mestrado. Universidade Federal de Santa Catarina.

Lemos-Rossi, M. A. G. (2002). Gêneros discursivos no ensino de leitura e produção textual. Taubaté: Cabral. Editora Universitária.

Rodrigues. R. H. (1999). As diferentes esferas sócio-discursivas como critério para a elaboração de currículos. Intercâmbio, 8, 93-100.

(2005). Os gêneros do discurso na perspectiva dialógica da linguagem: a abordagem de Bakhtin. In: J. L. Meurer, A. Bonini \& D. Motta-Roth (Orgs.). Gêneros: Teorias, métodos e debates. (pp. 152-183). São Paulo: Parábola Editorial.

Rojo, R. (1996). Perspectivas enunciativo-discursivas em produção de textos. Anais, Congresso de Linguística Aplicada, 4. (pp. 285-290). Campinas: DLA/IEL/UNICAMP.

- (2001). A teoria dos gêneros em Bakhtin: Construindo uma perspectiva enunciativa para o ensino de compreensão e produção de textos na escola. In: B. Brait (Org.). Estudos enunciativos no Brasil: Histórias e perspectivas. São Paulo: Fapesp.

\section{A AUTORA}

Nívea Rohling da Silva é Graduada em Letras pela Universidade da Região de Joinville - UNIVILLE (2003). É mestre em Linguística pela Universidade Federal de Santa Catarina - UFSC (2007) e doutoranda em Linguística pela mesma universidade. Desenvolve atividades de ensino e pesquisa. Pesquisa temas como: Análise do Discurso, Gêneros do Discurso e Letramento. É integrante do Grupo de Pesquisa "Os Gêneros do Discurso - Práticas Pedagógicas e Análise de Gêneros" e do projeto: "Estudo dos gêneros do discurso jornalísticos: análises na perspectiva bakhtiniana da linguagem" da Pós-Graduação da UFSC. E-mail: niveajoi@yahoo.com.br. 